\title{
Synthesis of DTCX:
}

25,27-diethyl-dithiocarbamic-26,28-dihidroxy-p-tert-butylcalix[4]arene (DTCX) was was prepared from 25,27-diethylamino-26,28-dihidroxy-p-tert-butylcalix[4]arene $(\mathrm{AmCX})$ following a modified method of that described by Zhao et al. ${ }^{10}$, by exposing the initial amino compounds to an excess of $\mathrm{CS}_{2}$ in methanol. The exact procedure was as follows: $1 \mathrm{~mL}$ of a $10 \%$ solution of $\mathrm{CS}_{2}$ in methanol was added drop by drop to a 3.7 $\mathrm{mL}$ of $5.0^{*} 10^{-3} \mathrm{M}$ solution of $\mathrm{AmCX}$ in methanol under stirring. The white solid obtained was washed three times with water before preparing a $5 * 10^{-2} \mathrm{M}$ solution in acetone.

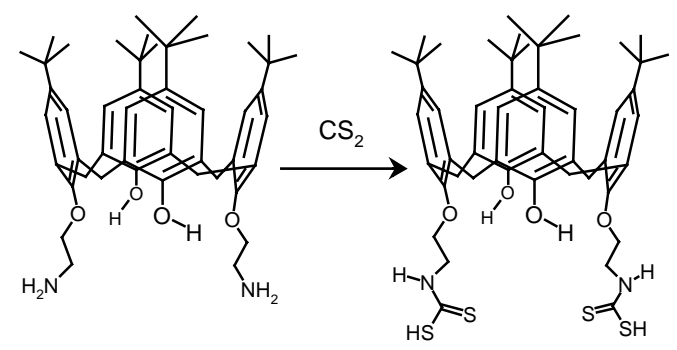

\section{Samples for SERS measurements:}

The sample for SERS was prepared by adding an aliquot of DTCX in acetone $\left(5 \times 10^{-2}\right.$ M) to the Ag nanoparticle suspension up to a final concentration of $5 \times 10^{-4} \mathrm{M}$. The $\mathrm{Ag}$ colloid was prepared by chemical reduction of $\mathrm{Ag}^{+}$using citrate as reducing agent in the following way: $1 \mathrm{~mL}$ of a $1 \% \mathrm{w} / \mathrm{v}$ tri-sodium citrate aqueous solution was added to 50 $\mathrm{mL}$ of a boiling $10^{-3} \mathrm{M}$ silver nitrate aqueous solution, and kept boiling for $1 \mathrm{~h}$. The colloid obtained showed a turbid gray aspect and has a final $\mathrm{pH}$ of 6.5. The silver colloid was previously aggregated by adding an aliquot of potassium nitrate solution for a final concentration of $3 \times 10^{-2} \mathrm{M}$. The DTCX-functionalized Ag nanoparticles were then exposed to the pollutant, by adding an aliquot of the pyrene solution to the 
colloidal suspension up to a final concentration of $10^{-7} \mathrm{M}$. The normal Raman and the SERS spectra were recorded with a Renishaw Raman Microscope System RM2000 equipped with a diode laser emitting at $785 \mathrm{~nm}$, while IR absorption spectra were recorded with a FTIR Bruker IFS 66 spectrometer provided with a DTGS detector. 

